\title{
A STUDY TO ASSESS THE LEVEL OF MENTAL HEALTH AMONG B.SC NURSING FIRST YEAR STUDENTS IN SRM COLLEGE OF NURSING, KATTANKULATHUR
}

\author{
DHANALAKSHMI S, USHAPRIYA MATHIAZHAKAN*, HEMAMALINI M
}

Department of Nursing, SRM College of Nursing, Kattankulathur, Kanchipuram, Tamil Nadu, India. Email: mowazh@gmail.com

Received: 25 May 2016, Revised and Accepted: 13 April 2017

ABSTRACT

Objectives: The present study aimed to determine the level of mental health adopted by $1^{\text {st }}$ year B.Sc. nursing students.

Methods: A total of $501^{\text {st }}$ year B.Sc., nursing students were selected using non-probability convenient sampling technique. The tools used for data collection were William C. Menninger mental health assessment scale, and socio-demographic pro forma.

Results: The studies revealed that $40(80 \%)$ students have moderate mental health, $10(20 \%)$ students have good mental health, and none of them have poor mental health. There is a significant association between the level of mental health among nursing students and with their demographic variable sex.

Conclusion: The nurse administrator should plan and organize an educational program for nursing students, to prepare them to cope up with any stressful situations. Hence, the researcher emphasizes the need for more research to improve the level of mental health and by applying the research finding for future.

Keywords: Assess, Mental health, Student, Nursing college.

(C) 2017 The Authors. Published by Innovare Academic Sciences Pvt Ltd. This is an open access article under the CC BY license (http://creativecommons. org/licenses/by/4. 0/) DOI: http://dx.doi.org/10.22159/ajpcr.2017.v10i7.13077

\section{INTRODUCTION}

Mental health is created in our interactions with the world around us [1], and these challenges pose a major problem for many undergraduate and graduate college students [2]. Good mental health protects us and helps us to avoid risk-taking behaviors that contribute to poor mental health [3] and impact college campuses in a variety of ways, including student health outcomes, academic performance, student retention, and graduation rates.

Mental health is a state of well-being in which an individual realizes his or her own abilities, can cope with the normal stresses of life, can work productively, and is able to make a contribution to his or her community [4] and have a negative impact on the health behaviors of college students [5]. Normal mental health or wellbeing implies that a person is reasonably happy and free of worry [6] and mental illness is a major concern yet nearly half of the students report receiving no education on mental health issues before starting college [7]

The researcher observed that students are mentally healthy and academically good when they join the course; however; as they advance in their education and training, they do suffer with various mental health problems, i.e., anxiety, depression, stress, maladjustment, drug abuse, or even commit suicide. This made the researcher curious to know whether the students suffering with mental health problems.

\section{METHODS}

The research design applied in this study was descriptive survey design. This study was conducted at the SRM College of Nursing, Kattankulathur, Tamil Nadu, India. Ethical clearance from the Institutional Ethics Committee approval (SRMCON/2015-2016/bsc/44) has been obtained. The sampling technique used in this study was nonprobability convenient sampling. The mental health questionnaire (William C. Menninger) 13 questions are used to assess the level of mental health. These questions are based on negative aspects. Those who chosen the options yes will be awarded zero mark. Those who chosen the option no will be awarded one mark. Interpretation of scores 13 means Good mental health, 7-12 means moderate mental health, and
0-6 means poor mental health. The obtained data from the respondents were tabulated with appropriate descriptive and inferential statistics. The descriptive statistics used are mean, percentage, and inferential statistics are Chi-square used to associate the quality of life.

Table 1 shows that among 50 nursing students, 40 (80\%) students have moderately mental health, 10 (20\%) students have good mental health, and none of them have poor mental health.

Table 2 reveals that there is a significant association between the level of mental health among nursing students and with their demographic variable sex. There is no association with respect to other variables.

\section{DISCUSSION}

The first objective of the study is to assess the level of mental health among nursing students. A similar study was conducted by Paul (2012) conducted a study was on Mental Health of Muslim Nursing Students in Thailand. Results indicated stress $(\beta=0.42)$ was positively associated with anxiety whereas self-esteem $(\beta=-0.42)$ was negatively associated with anxiety, together this model accounted for $46 \%$ of the variance in anxiety. Self-esteem $(\beta=-0.41)$ and social support $(\beta=-0.17)$ were negatively associated with depression whereas stress $(\beta=0.37)$ was positively correlated with depression, together this model accounted for $57 \%$ of the variance in depression [8]

The second objective of the study is to associate the level of mental health among nursing students with their demographic variables. A similar cross-sectional study was conducted by Revista (2010) on

Table 1: Assessment of the level of mental health among nursing students

\begin{tabular}{ll}
\hline Level of mental health & n (\%) \\
\hline Poor mental health & $0(0)$ \\
Moderate mental health & $40(80)$ \\
Good mental health & $10(20)$ \\
\hline
\end{tabular}


Table 2: Association between the level of mental health among nursing students with their demographic variables $(n=50)$

\begin{tabular}{|c|c|c|c|c|}
\hline \multirow[t]{2}{*}{ Demographic variables } & \multicolumn{3}{|c|}{ Level of mental health $n(\%)$} & \multirow[t]{2}{*}{ Chi-square test } \\
\hline & Poor mental health & Moderately mental health & Good mental health & \\
\hline \multicolumn{5}{|l|}{ Age (years) } \\
\hline 18 & $0(0)$ & $34(85)$ & $9(90)$ & $\chi^{2}=0.166$ \\
\hline \multirow[t]{2}{*}{19} & $0(0)$ & $4(15)$ & $1(10)$ & $\mathrm{p}=0.684$ \\
\hline & & & & NS \\
\hline \multicolumn{5}{|l|}{ Sex } \\
\hline Male & $0(0)$ & $2(5)$ & $3(30)$ & $\chi^{2}=8.666$ \\
\hline \multirow[t]{2}{*}{ Female } & $38(95)$ & $7(70)$ & $1(7.2)$ & $\mathrm{p}=0.018$ \\
\hline & & & & S \\
\hline \multicolumn{5}{|l|}{ Education of fathers } \\
\hline Primary & $0(0)$ & $7(17.5)$ & $1(10)$ & $\chi^{2}=4.68$ \\
\hline Secondary & $0(0)$ & $6(15)$ & $2(20)$ & $\mathrm{p}=0.321$ \\
\hline High school & $0(0)$ & $12(30)$ & $4(40)$ & NS \\
\hline Higher secondary & $0(0)$ & $10(25)$ & $0(0)$ & \\
\hline Degree & $0(0)$ & $5(12.5)$ & $3(30)$ & \\
\hline \multicolumn{5}{|l|}{ Education of mothers } \\
\hline Non formal education & $0(0)$ & $3(7.5)$ & $0(0)$ & $\chi^{2}=2.20$ \\
\hline Primary & $0(0)$ & $2(5)$ & $1(10)$ & $p=0.82$ \\
\hline Secondary & $0(0)$ & $8(20)$ & $1(10)$ & NS \\
\hline High school & $0(0)$ & $15(37.5)$ & $4(40)$ & \\
\hline Higher secondary & $0(0)$ & $4(10)$ & $2(20)$ & \\
\hline Degree & $0(0)$ & $8(20)$ & $2(20)$ & \\
\hline \multicolumn{5}{|l|}{ Occupation of fathers } \\
\hline Public sector & $0(0)$ & $7(17.5)$ & $1(10)$ & $\chi^{2}=4.33$ \\
\hline Private sector & $0(0)$ & $11(27.5)$ & $1(10)$ & $p=0.38$ \\
\hline Self employed & $0(0)$ & $10(25)$ & $5(50)$ & NS \\
\hline Un employed & $0(0)$ & $4(10)$ & $0(0)$ & \\
\hline Business & $0(0)$ & $8(20)$ & $3(30)$ & \\
\hline \multicolumn{5}{|l|}{ Type of family } \\
\hline Nuclear & $0(0)$ & $32(80)$ & $10(100)$ & $\chi^{2}=2.38$ \\
\hline \multirow[t]{2}{*}{ Joint } & $0(0)$ & $8(20)$ & $0(0)$ & $\mathrm{p}=0.12$ \\
\hline & & & & NS \\
\hline \multicolumn{5}{|c|}{ No. of members in the family } \\
\hline & $0(0)$ & $11(27.5)$ & $5(50)$ & $\chi^{2}=1.867$ \\
\hline \multirow{2}{*}{$>2$} & $0(0)$ & $29(72.5)$ & $5(50)$ & $p=0.17$ \\
\hline & & & & NS \\
\hline
\end{tabular}

S: Significant, NS: Not significant

common mental disorders among medical students at Universidade Federal de Sergipe. The result shows that the general prevalence of common mental disorder was $40 \% \quad(n=473)$ after exclusion of the freshmen it increased to $42.5 \%$ among students from the secondto the $12^{\text {th }}$ semester. It was higher among those who did not have faith in their acquisition of the skills needed to become a good doctor (odds ratio [OR] $=2.82$ ) who felt less comfortable about course activities $(\mathrm{OR}=3.75)$ who considered themselves emotionally stressed $(\mathrm{OR}=2.14)$ among those who did not consider themselves happy (OR=2.85), who believed that the course did not match their expectations $(\mathrm{OR}=1.64)$ [9].

\section{CONCLUSION}

The findings of the present study reveal that among 50 nursing students, $40(80 \%)$ students have moderate mental health, $10(20 \%)$ students have good mental health, and none of them have poor mental health, and there is significant association between the level of mental health among nursing students and with their demographic variable sex.

\section{ACKNOWLEDGMENT}

We sincere thank Dean, SRM College of Nursing, for granting permission to conduct the study. We acknowledge all the participants for their participation and cooperation.

\section{REFERENCES}

1. Available from: http://www.who.int/features/factfiles/mental health/en.

2. Gallagher R. National Survey of Counselling Centre Directors 2011, Monograph Series No. 8T. Alexandria, VA: International Association of Counselling Services; 2011.

3. Swami V, Chamorro-Premuzic T, Sinniah D, Maniam T, Kannan K, Stanistreet D, et al. General health mediates the relationship between loneliness, life satisfaction and depression. A study with Malaysian medical students. Soc Psychiatry Psychiatr Epidemiol 2007;42(2):161-6.

4. Whitlock J, Eckenrode J, Silverman D. Self-injurious behaviors in a college population. Pediatrics 2006;117(6):1939-48.

5. Kesseler RC, Berglund P, Demler O, Jin R, Kathleen KR, Walters EE. Lifetime prevalence and age-of-onset distributions of DSM-IV disorders in the National Comorbidity Survey Replication. Arch Gen Psychiatry 2005;62(6):593-602.

6. Andrews B, Wilding JM. The relation of depression and anxiety to lifestress and achievement in students. Br J Psychol 2004;95:509-21.

7. Galvin J, Smith AP. Stress in UK mental health training: A multidimensional comparison study. Br J Educ Soc Behav Sci 2015; 9(3):161-75.

8. Behere SP, Yadav R, Behere PB. A comparative study of stress among students of medicine, engineering, and nursing. Indian J Psychol Med 2011;33(2):145-8.

9. Roeses RW, Midgley C. Study on teachers views of issues involving students mental health. J Educ Psychol 1996;88(3):408-22. 